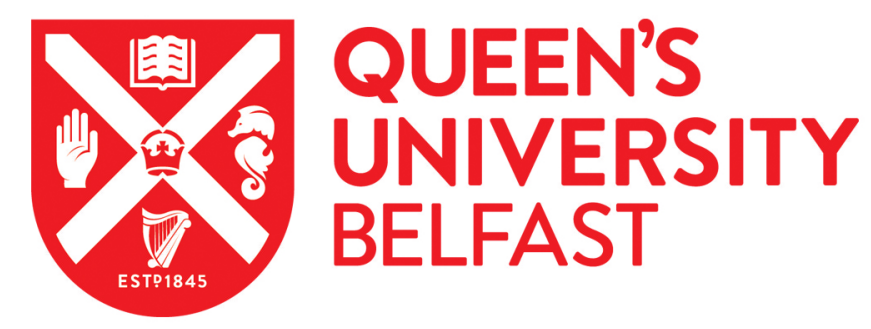

\title{
Robust Room Temperature Hysteresis in an Felll Spin Crossover Metallomesogen
}

Fitzpatrick, A. J., Martinho, P. N., Gildea, B. J., Holbrey, J. D., \& Morgan, G. G. (2016). Robust Room

Temperature Hysteresis in an Felll Spin Crossover Metallomesogen. European Journal of Inorganic Chemistry, 2016(13-14), 2025-2029. https://doi.org/10.1002/ejic.201501335

Published in:

European Journal of Inorganic Chemistry

Document Version:

Peer reviewed version

Queen's University Belfast - Research Portal:

Link to publication record in Queen's University Belfast Research Portal

Publisher rights

Copyright @ 2015 WILEY-VCH Verlag GmbH \& Co. KGaA, Weinheim

This is the peer reviewed version of the following article: Fitzpatrick, A. J., Martinho, P. N., Gildea, B. J., Holbrey, J. D. and Morgan, G. G. (2015), Robust Room Temperature Hysteresis in an Felli Spin Crossover Metallomesogen. Eur. J. Inorg. Chem, which has been published in final form at http://onlinelibrary.wiley.com/doi/10.1002/ejic.201501335/abstract. This article may be used for non-commercial purposes in accordance With Wiley-VCH Terms and Conditions for self-archiving

\section{General rights}

Copyright for the publications made accessible via the Queen's University Belfast Research Portal is retained by the author(s) and / or other copyright owners and it is a condition of accessing these publications that users recognise and abide by the legal requirements associated with these rights.

\section{Take down policy}

The Research Portal is Queen's institutional repository that provides access to Queen's research output. Every effort has been made to ensure that content in the Research Portal does not infringe any person's rights, or applicable UK laws. If you discover content in the

Research Portal that you believe breaches copyright or violates any law, please contact openaccess@qub.ac.uk. 


\title{
Robust Room Temperature Hysteresis in an Fe(III) Spin Crossover Metallomesogen
}

\author{
Anthony J. Fitzpatrick, ${ }^{a}$ Paulo N. Martinho, ${ }^{a}$ Brendan J. Gildea, ${ }^{a}$ John D. Holbrey, ${ }^{b}$ and Grace G. \\ Morgan*a \\ Dedication ((optional))
}

\begin{abstract}
The high temperature magnetic and structural properties of an amphiphilic iron(III) spin crossover complex are reported. Thermal cycling reveals a scan rate-dependent $20 \mathrm{~K}$ thermal hysteresis in the $\chi_{m} T$ vs $T$ data close to room temperature. A fast scan rate is essential for the hysteresis but it is robust and reproducible after multiple thermal cycles. Differential scanning calorimetry and cross polarized microscopy are used to show that the magnetic switching aligns with a material state change from solid to ordered liquid phase on warming.
\end{abstract}

\section{Introduction}

Spin crossover (SCO) is an intrinsically interesting electronic phenomenon which yields switchable materials making them ideal candidates for potential devices. ${ }^{[1]}$ The combination of a functional material with SCO to yield multifunctional materials has been a very active area of research in the last decade. Examples of the enhanced functionality range from porous frameworks for sensing and solvation control, ${ }^{[2]}$ through electrical conductivity, ${ }_{,}^{[3]}$ to photo-optic effects such as non-linear optics. ${ }^{[4]}$ One such combination of properties that has been explored in detail is the incorporation of metallomesogenic properties with SCO. [5] Metallomesogens are metal complexes that can exhibit liquid crystalline properties. Diamagnetic metals can be used, therefore mimicking the well-known thermotropic and lyotropic mesophases of classical organic and ionic compounds. However, perhaps more interestingly, many examples of paramagnetic metallomesogens have been published in recent years. ${ }^{[6]}$ Not only do these complexes exhibit a variety of liquid crystalline phases but in some cases they can also be strongly aligned by an applied magnetic field. In several examples the application of a magnetic field changes the nature of the liquid crystalline mesophase. Such materials therefore have the potential for coupling both the bulk physical state of matter and the magnetic spin state. In SCO systems these hybrid materials can be divided into three types of behaviour dictated by the interplay between the SCO and LC

[a] A. J. Fitzpatrick, P. N. Martinho, B. J. Gildea, G. G. Morgan Centre for Synthesis and Chemical Biology, School of Chemistry, University College Dublin

Belfield, Dublin 4, Ireland.

E-mail: grace.morgan@ucd.ie

[b] J. D. Holbrey

School of Chemistry and Chemical Engineering

Queen's University Belfast

Stranmillis Road, Belfast

Belfast BT9 5AG, UK.

Supporting information for this article is given via a link at the end of the document.((Please delete this text if not appropriate)) properties. ${ }^{[5]}$ Type 1 describes a coupled LC/SCO transition, Type 2 , describes an uncoupled LC/SCO transition that occurs in the same temperature range, and finally Type 3 describes a fully uncoupled LC and SCO transition. Fully coupled transitions, Type 1 , can lead to greater control of the spin switching properties of the material, which are ideal for devices and applications. We have focused our investigations on the paramagnetic $3 d^{6}$ iron(III) ion which can adopt both HS $(S=5 / 2)$ and $L S(S=1 / 2)$ states. In the right ligand environment iron(III) complexes can switch between the two electronic states by application of external perturbations such as temperature, pressure or light. Here, we have restricted investigations to thermally induced SCO. The cationic iron(III) complex with sal $_{2}$ trien $^{[7]}$ is a well-known prototype for materials development. ${ }^{[8]}$ We have previously reported that $\mathrm{C}_{6}$, $\mathrm{C}_{12}$ and $\mathrm{C}_{18}$ alkylation of $\mathrm{HS} \mathrm{Fe}(\mathrm{III})$ complex [Fe(sal) $)_{2}$ trien][BF $\left.\mathrm{BF}_{4}\right]$ switches on the SCO characteristic in this complex and that the thermal magnetic behaviour of the resulting amphiphilic compounds is sensitive to the length of the alkyl chains. ${ }^{[9]}$ The $C_{12}$ alkylated complex also allows for the formation of nanowires by template methods. ${ }^{[10]}$ Here we report the physical and magnetic properties of the $\mathrm{C}_{18}$ alkylated complex (1) above $300 \mathrm{~K}$ where it exhibits a liquid crystalline phase and opening of a scan-rate dependent hysteresis window centered at $310 \mathrm{~K}$.

\section{Results and Discussion}

\section{Synthesis}

The Fe(III) complex (1) was prepared as previously described ${ }^{[9]}$ by condensation of triethylenetetramine (trien) with salicylaldehyde followed by functionalisation of the amine nitrogen atoms of the ligand backbone with octadecane alkyl chains. The derivatised ligand was reacted with $\mathrm{Fe}\left(\mathrm{BF}_{4}\right)_{2} \cdot 6 \mathrm{H}_{2} \mathrm{O}$ which after aerial oxidation and column purification yielded the $\mathrm{Fe}(\mathrm{III})$ complex (1), Scheme 1.
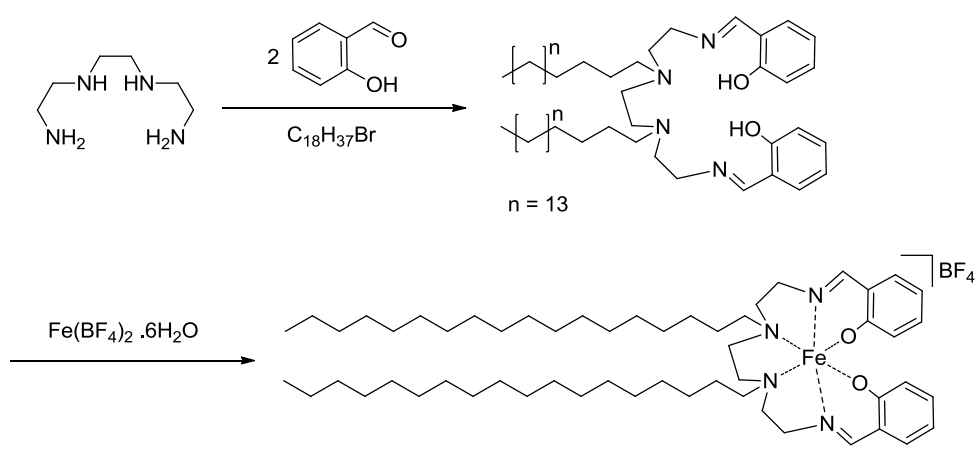

Scheme 1: Synthesis of complex (1). 
EPR Characterisation: The thermal SCO in the solid state was confirmed by X-band EPR studies between 293 and $113 \mathrm{~K}$, Figure 1. The solid state EPR spectrum of (1) at $293 \mathrm{~K}$ is characteristic for $\mathrm{HS} \mathrm{Fe}(\mathrm{III})^{[11]}$ with weak signals at $\mathrm{g}=6.0$ and $\mathrm{g}=2.2$. On decreasing the temperature the LS signal starts to predominate although the HS feature at $g=6.0$ persists. A characteristic LS signal ${ }^{[11]}$ grows in at $\mathrm{g}=2.1$ from $233 \mathrm{~K}$ in cooling mode, Figure 1 .

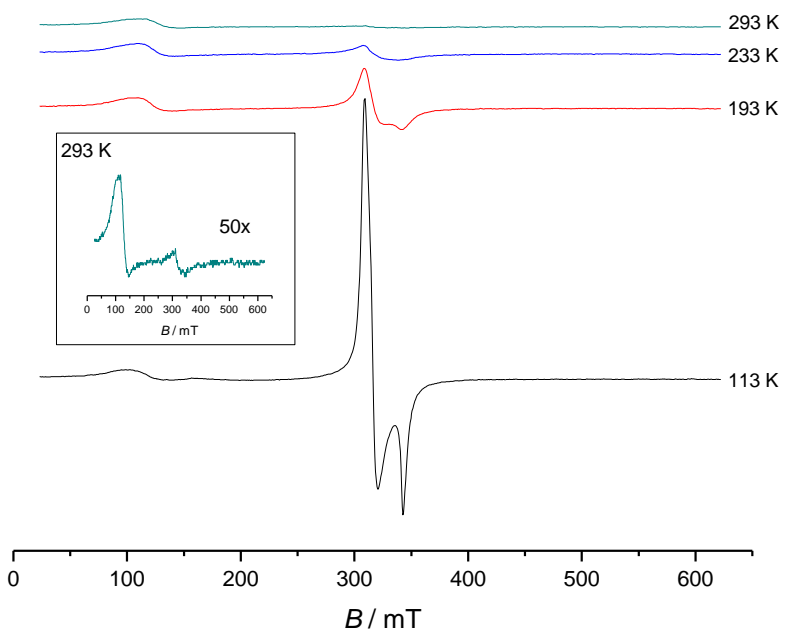

Figure 1. Solid state variable temperature EPR spectra of (1). X-band EPR were recorded at $9.430 \mathrm{GHz}$ with magnetic field centred at $322.5 \mathrm{mT}$ and a field sweep of $600 \mathrm{mT}$. A modulation amplitude of $0.7 \mathrm{mT}$ was used in conjunction with a microwave power of $0.1 \mathrm{~mW}$ and a gain of 10 .

The thermal dependence of the $\chi_{m} T$ value of (1) was previously reported by us in $2012^{[9]}$ where the sample was measured between $10-300 \mathrm{~K}$ at $10 \mathrm{~K} \mathrm{~min}^{-1}$ in cooling mode only, revealing a gradual SCO. Here the magnetic characterisation was extended by measuring up to $380 \mathrm{~K}$ in cooling and warming modes, which revealed the existence of a $10 \mathrm{~K}$ hysteresis window centred at 310 $\mathrm{K}$, Figure 2, above the maximum temperature of the previously reported measurement. The nature of the hysteresis and the relationship between magnetic properties and physical state above $300 \mathrm{~K}$ was further probed by variable scan-rate magnetic measurements between 380-260 $\mathrm{K}$ and Differential Scanning Calorimetry (DSC) between $278-473 \mathrm{~K}$. The sequence of experiments are described below.

First Magnetic Scan at $10 \mathrm{~K} \mathrm{~min}^{-1}$ : In the initial sequence the sample was cooled from $300 \mathrm{~K}$ to $10 \mathrm{~K}$, then heated to $380 \mathrm{~K}$ before one final cycle of cooling to $10 \mathrm{~K}$ and heating again to 380 $\mathrm{K}$ all with a scan rate of $10 \mathrm{~K} \mathrm{~min}^{-1}$, Figure 2. The drop in $\chi_{\mathrm{m}} T$ above $348 \mathrm{~K}$ in the first heating experiment to $380 \mathrm{~K}$ suggests a phase change in the material, as the moment drops from $2.8 \mathrm{~cm}^{3}$ $\mathrm{mol}^{-1} \mathrm{~K}$ at $348 \mathrm{~K}$ to $2.3 \mathrm{~cm}^{3} \mathrm{~mol}^{-1} \mathrm{~K}$ by $360 \mathrm{~K}$. This fall in the $\chi_{m} T$ value over a $12 \mathrm{~K}$ range is attributed to loss of solvent in the sample. The moment recovers on further heating above $360 \mathrm{~K}$ and reaches a value of $2.72 \mathrm{~cm}^{3} \mathrm{~mol}^{-1} \mathrm{~K}$ by $380 \mathrm{~K}$. The apparent drop in the $\chi_{m} T$ value between $348-360 \mathrm{~K}$ is therefore likely due to non-uniformity of sample distribution in the semi-solid material over this temperature range which will affect how the spins are detected in the SQUID. On cooling from $380 \mathrm{~K}$ to $10 \mathrm{~K}$ a gradual $\mathrm{SCO}$ is again observed but with a different profile to that recorded in the initial cooling sequence. This new profile persists on the final sequence of re-warming back from $10 \mathrm{~K}$ to $380 \mathrm{~K}$ at $10 \mathrm{~K} \mathrm{~min}$ ${ }^{1}$. In the final cooling and heating cycles at $10 \mathrm{~K} \mathrm{~min}^{-1}$ between $380-10 \mathrm{~K}$, a $10 \mathrm{~K}$ hysteresis window opens just above room temperature at $310 \mathrm{~K}$, suggesting the existence of an ordered mesophase in this temperature regime.

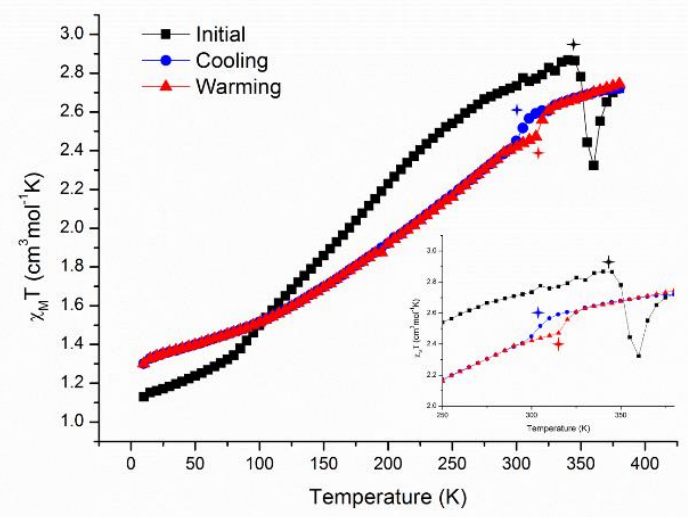

Fig. 2: Plot of $X_{m} T \vee \mathrm{T}$ plot for complex 1, illustrating the change in SCO profile which results after heating to $380 \mathrm{~K}$

DSC and Polarized Microscopy Characterisation: Complex (1) was further investigated by DSC where on first heating at $5 \mathrm{~K} \mathrm{~min}^{-1}$ two broad endothermic transitions at (i) $322.0 \mathrm{~K}$ (onset $316.1 \mathrm{~K}$, $38.2 \mathrm{~kJ} \mathrm{~mol}-1$ ) and (ii) $347.4 \mathrm{~K}$ (onset $338.3 \mathrm{~K}, 7.9 \mathrm{~kJ} \mathrm{~mol}-1$ ) with a single sharp exothermic freezing transition at $307.3 \mathrm{~K}$ (onset 308.7 K, 16.6 kJ mol-1) on cooling, were observed, Figure. 3.

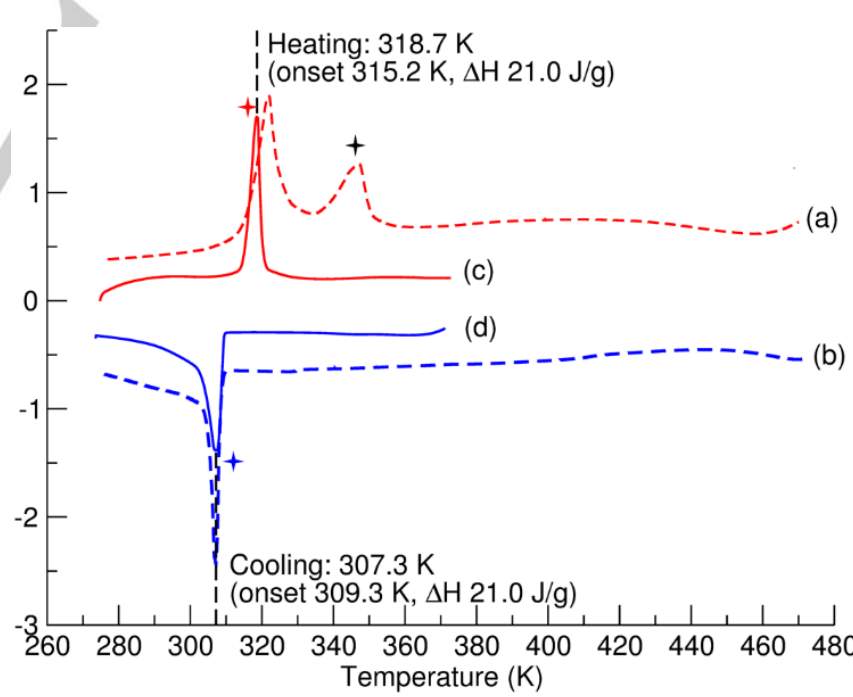

Fig. 3: Differential scanning calorimetry of (1) between $318-480 \mathrm{~K}$ in warming and cooling modes at $5 \mathrm{~K} \mathrm{~min}^{-1}$.

A broad inflection at ca. $450 \mathrm{~K}$ (reversible on cooling) can also be observed, however there is no distinct first order clearing transition. The DSC results indicate that (1) has some degree of reversible thermal polymorphism. However, whether this corresponds to crystal-crystal structural reorganisation, to melting to an isotropic liquid or to the formation of plastic crystals or liquid 
crystals could not be directly determined. On the second, and subsequent cycles, a repeatable and reversible melting and crystallising transition at $318.7 \mathrm{~K}$ (heating) and $309.3 \mathrm{~K}$ (cooling) was observed.

Polarized Optical Microscopy (POM) was also used to investigate the phase change above $318 \mathrm{~K}$. In the region of this transition (318-350 K), the crystalline complex (1) softened significantly to produce a viscous paste that could be deformed and sheared by compression and movement of the microscope cover-slides, but did not produce a free-flowing liquid. Fig. 4 shows a picture of the phase appearance of (1) under crossed polarisers at $373 \mathrm{~K}$.

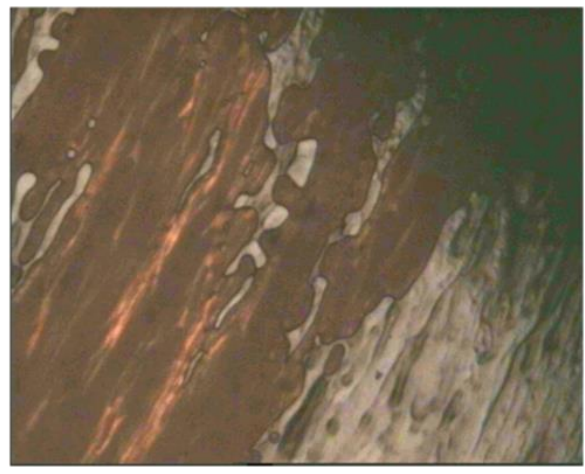

Fig. 4: View of complex 1 under cross polarizers at $373 \mathrm{~K}$.

Although the phase texture is not well developed (a consequence of the extremely high viscosity of the material), anisotropy can be observed consistent with an intermediate liquid crystalline phase. The nature of the hysteretic loop in the magnetic data can therefore be correlated with the phase change in the complex. As such further susceptibility measurements were carried out to investigate the effect of variable temperature scan rates.

Second Magnetic Scan with Variable Rates: The scan rate used in the initial magnetic data collection was $10 \mathrm{~K} \mathrm{~min}^{-1}$. After the first cycle of magnetic measurements a second set were completed at scan rates of 10.0,5.0, 2.0, 1.0, 0.5 and $0.1 \mathrm{~K} \mathrm{~min}^{-1}$ with a temperature cycle of $380-260-380 \mathrm{~K}$ and the results are shown in Fig. 5. The chief effect of reducing the scan rate is to flatten the SCO profile, i.e. to reduce the change in the absolute number of unpaired spins with temperature, but the $20 \mathrm{~K}$ hysteresis window persists with a fairly constant width at all scan rates until the data collection is slowed right down to $0.1 \mathrm{~K} \mathrm{~min}^{-1}$. The first scan at $10.0 \mathrm{~K} \mathrm{~min}^{-1}$ mimics the original data collection described in the first section and there is no change in the HS:LS fractions or the hysteresis width on halving the scan rate to $5.0 \mathrm{~K}$ $\mathrm{min}^{-1}$. Although reduction of the scan rate to $2.0,1.0$ and $0.5 \mathrm{~K}$ $\mathrm{min}^{-1}$ results in a less pronounced spin state change the hysteresis loop persists. Moreover there is good alignment of the temperature window of the spin state switching, Fig. 4 and the phase change as measured by DSC at $5 \mathrm{~K} \mathrm{~min}^{-1}$, Fig. 3. All of this suggests a direct relationship between the liquid crystalline properties and the thermal spin state switching in complex (1). This is important as it opens an avenue for control of the hysteresis loop. Hysteresis loops in solid samples of SCO complexes are known to have scan rate dependence which is generally manifest as a narrowing of the loop with little or no change in the percentage of HS and LS sites at the temperature extremes. Changing the scan rate in such samples has the effect of altering the temperature of the transition in heating or cooling mode or both, but not the $\chi_{\mathrm{m}} T$ value. In the metallomesogen complex (1) the spin state change occurs over a temperature range coincident with that of a phase change from solid to liquid crystalline, i.e. it is a Type I SCO metallomesogen. ${ }^{[6 \mathrm{~d}]}$ In complex (1) the associated hysteresis loop maintains its width over many scan rates, but the value of $\chi_{m} T$ changes. This suggests that the hysteresis originates because of the physical state change from solid to liquid crystalline which changes the density of the sample. A percentage spin state change follows, the degree of which is dependent on the scan rate, but not on the onset and final temperatures, which are instead dictated by the melting and freezing temperatures.

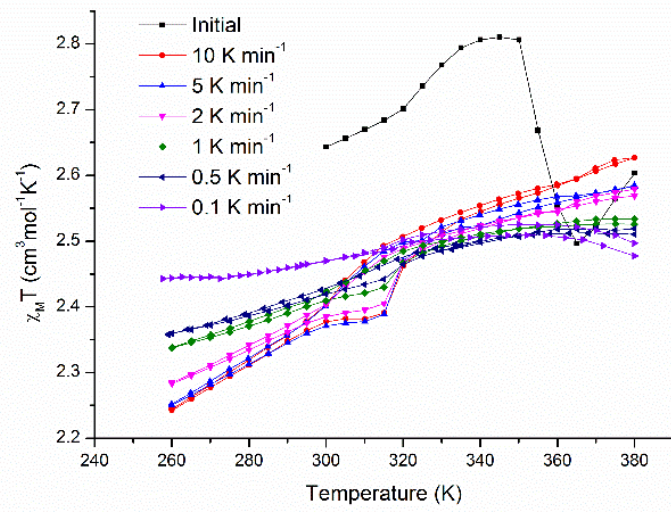

Figure 5: $\chi_{m} T \vee \mathrm{T}$ plot for complex 1 with variable scan rate measurements between 380 and $260 \mathrm{~K}$.

Phase Stability Studies at Fixed Temperature:-The hysteresis appears to be driven by the material phase change and the different temperatures of melting and freezing. The effect on the spin state switching is narrowing of the $\chi_{m} T$ values as the scan rate is slowed. A time-dependent magnetometry study was next carried out on complex (1) to investigate the stability of the solid and liquid phases. The measurement consisted of cooling to 310 $\mathrm{K}$ at $10 \mathrm{~K} \mathrm{~min}^{-1}$ i.e. at the lower temperature part of the hysteresis loop, and then recording susceptibility data over $21 \mathrm{hr}$ while keeping the temperature fixed, Fig. 6a. This allowed us to probe if the slow relaxation occurred when the temperature was constant. The cooling time study revealed that the $\chi_{m} T$ value falls steadily while the temperature is held at $310 \mathrm{~K}$ until it converges to a constant value of $2.25 \mathrm{~cm}^{3} \mathrm{~mol}^{-1} \mathrm{~K}$ after around 6 hours, Figs. $6 \mathrm{a}$ and $6 \mathrm{~b}$. This value is in line with the $\chi_{\mathrm{m}} T$ value at $310 \mathrm{~K}$ in the warming cycles at 10.0, 5.0 and $2.0 \mathrm{~K} \mathrm{~min}^{-1}$, Fig 5. From this it can be assumed that the slow reorganisation associated with the solidification of complex (1) cannot be stalled by holding the temperature. The change in $\chi_{m} T$ value starts immediately when cooling is switched off, i.e. there is no induction time, and the relaxation back to the thermodynamically stable $\chi_{m}$ T value of 2.25 $\mathrm{cm}^{3} \mathrm{~mol}^{-1} \mathrm{~K}$ is complete after ca. $350 \mathrm{~min}$. After 21 hours of keeping the temperature constant at $310 \mathrm{~K}$, Fig 6b, the sample was cooled to $260 \mathrm{~K}$ at $10 \mathrm{~K} \mathrm{~min}^{-1}$ and heated back to $310 \mathrm{~K}$ at the same scan rate, Figs. $6 \mathrm{a}$ and $6 \mathrm{~b}$. It is clear that the profile of the thermal evolution between $260-310 \mathrm{~K}$, Fig $6 \mathrm{a}$ matches that of 
the original scan rate experiments at 10.0, 5.0 and $2.0 \mathrm{~K} \mathrm{~min}^{-1}$ shown in Fig. 5. After warming to $310 \mathrm{~K}$ the sample was again held at this temperature, also for $21 \mathrm{hr}$, before warming to $380 \mathrm{~K}$. This resulted in a higher transition temperature (between 325-330 $\mathrm{K})$ compared to the original temperature cycling experiments (320 $\mathrm{K})$, Fig.5, presumably due to equilibration of the metallmesogen phase during the $21 \mathrm{hr}$ holding time. This once again highlights the interplay between the magnetic profile of the complex and its ordered liquid crystalline properties.
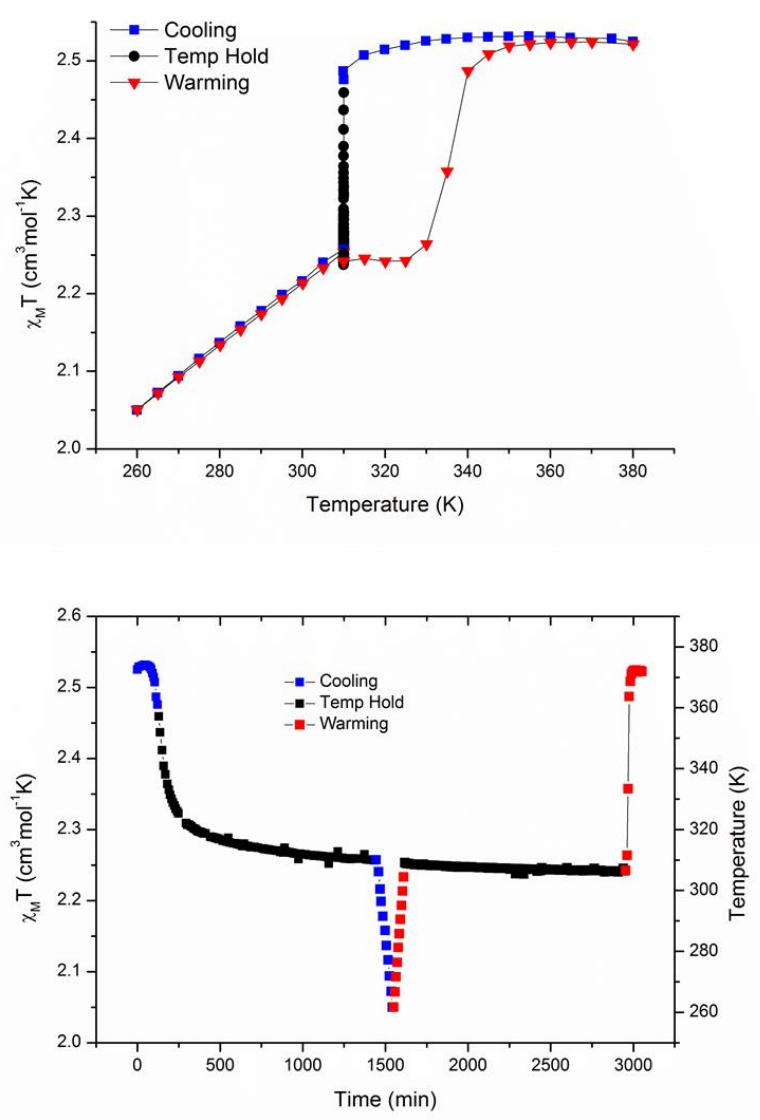

Fig. 6. a) $\chi_{m} T \vee T$ plot for complex (1) highlighting the time dependence of the spin state at fixed temperature; b) Plots of $\chi_{m} T v$ time and T $v s$ time for complex (1).

Post-cycling Test of Hysteresis Reproducibility: Magnetic stability and reproducibility are essential characteristics in SCO candidates for materials applications. A final measurement was therefore carried out, using the same parameters as the original $10 \mathrm{~K} \mathrm{~min}^{-1}$ cycle. The resultant thermal profile was in excellent agreement with the initial cycling at this fast scan rate, Fig. 7 . One minor difference in the post cycling/time study is that the $\chi_{m} T$ value in the high temperature regime after the hysteresis is slightly lower than that in the original data. This can be attributed to possible preorganization in the liquid-crystalline phase prior to the measurement. This would suggest that some organisation of the complexes can be "remembered" and as such this may open new avenues for preparation of memory devices based on physical orientation.

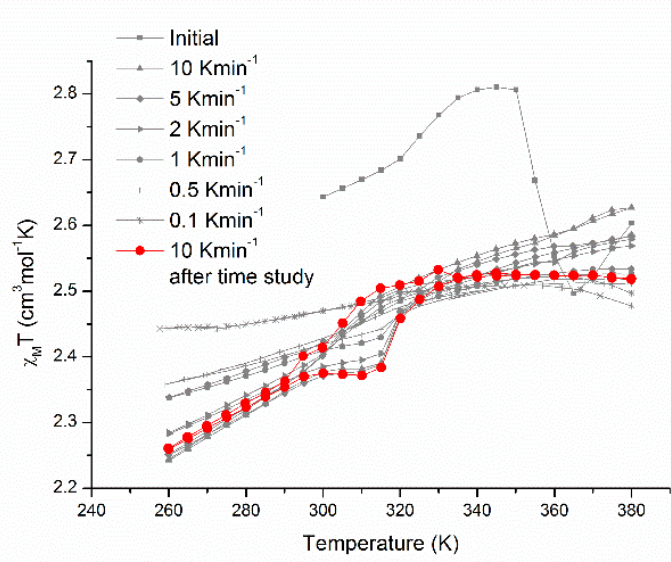

Fig. 7: $\chi_{m} T$ plots for the initial cycling (grey) and the $10 \mathrm{~K} \mathrm{~min}^{-1}$ plot after both the scan rate cycling and time studies (red).

\section{Conclusions}

The magnetic profile of an $\mathrm{Fe}$ (III) amphiphilic compound with pairs of $\mathrm{C}_{18}$ alkyl chains on the ligand has been investigated across a wide temperature range to include different material phases (solid and ordered liquid). The spin state switching in complex (1) shows a hysteresis loop close to room temperature (centered at $310 \mathrm{~K})$. DSC analysis reveals this is coincident with a material phase change from solid to liquid and POM suggests that the liquid phase is ordered. The DSC also indicates that the phase change is endothermic, consistent with crystal structure reorganisation or with melting. It also could be attributed to thermal polymorphism or formation of a plastic crystalline phase or finally, and most interestingly, a liquid crystalline phase. The polarised optical microscopy measurement tends to suggest that the compound shows liquid crystalline behaviour. However the very viscous nature of (1) did not give real opportunities for direct phase identification. Most interestingly the hysteresis in this metallomesogen is at a useful temperature and survives multiple cycles of warming and cooling. A fast scan rate is essential for hysteresis which can then be reliably switched on. Use of soft matter derivatives of SCO complexes may then be a good route to overcome the lack of reproducibility in the spin switching profile which is typically associated with crystalline samples.

\section{Experimental Section}


Complex 1 was prepared as reported previously. ${ }^{[9]}$ Yield $940 \mathrm{mg}$, (47\%).IR ( $\left.\mathrm{cm}^{-1}\right)(\mathrm{KBr}): \bar{v}=3427(\mathrm{vw}), 2917(\mathrm{~m}), 2850(\mathrm{~m}), 1771$ (vw), 1628 (s), 1544 (s), 1469 (s), 1445 (s), $1410(\mathrm{~m}), 1377(\mathrm{w})$, $1338(\mathrm{w}), 1306(\mathrm{~s}), 1199(\mathrm{~m}), 1152(\mathrm{~m}), 1064(\mathrm{~m}), 1036(\mathrm{~m}), 901$ $(\mathrm{w}), 800(\mathrm{w}), 761(\mathrm{~m}), 720(\mathrm{w}), 607(\mathrm{w}), 522(\mathrm{vw})$. Elemental analysis: $\mathrm{C}_{56} \mathrm{H}_{96} \mathrm{BF}_{4} \mathrm{FeN}_{4} \mathrm{O}_{2}$ (1000.04): calcd. C 67.26, $\mathrm{H}$ 9.68, N 5.60; found C 67.19, H 9.61, N 5.40.

\section{Acknowledgements}

We thank the following for their generous support: Science Foundation Ireland for Investigator Project Award 12/IP/1703 (G. G. M), the EU-COST action on spin state reactivity (CM1305) (G. G. M.), the National University of Ireland and the Cultural Service of the French Embassy in Ireland for scholarships (A.J.F) and the Irish Higher Education Authority for funding a SQUID magnetometer. The generous support of University College Dublin is also gratefully acknowledged.

Keywords: spin crossover • iron(III) $\cdot$ metallomesogen $•$ liquid crystalline $\cdot$ hysteresis

\section{References}

[1] a) M. A. Halcrow, Spin-crossover materials: properties and applications, John Wiley \& Sons, 2013; b) P. Gütlich, A. B. Gaspar, Y. Garcia, Beilstein J. Org. Chem. 2013, 9, 342-391. c) J.-F. Létard, P. Guionneau and L. Goux-Capes, Top. Curr. Chem., 2004, 221-249; d) P. Gütlich and H. A. Goodwin, Top. Curr. Chem. 2004, 1-47; e) O. Kahn and C. J. Martinez, Science 1998, 279, 44-48; f) O. Kahn, Curr. Opin. Solid State Mater. Sci. 1996, 1, 547-554.

[2] a) P. D. Southon, L. Liu, E. A. Fellows, D. J. Price, G. J. Halder, K. W. Chapman, B. Moubaraki, K. S. Murray, J.-F. Létard and C. J. Kepert, J. Am. Chem. Soc. 2009, 131, 10998-11009; b) C Bartual-Murgui, L. Salmon, A. Akou, N. A. Ortega-Villar, H. J. Shepherd, M. C. Muñoz, G. Molnár, J. A. Real and A. Bousseksou, Chem. Eur. J., 2012, 18, 507-516; c) F. J. MuñozLara, A. B. Gaspar, M. C. Muñoz, M. Arai, S. Kitagawa, M. Ohba and J. A. Real, Chem. Eur. J. 2012, 18, 8013-8018; d) E. Coronado and G. Minguez Espallargas, Chem. Soc. Rev. 2013, 42, 1525-1539; e) J. E. Clements, J. R. Price, S. M. Neville and C. J. Kepert, Angew. Chem. 2014, 126, 10328-10332; f) M. C. Young, E. Liew and R. J. Hooley, Chem. Commun. 2014, 50, 5043-5045.

[3] a) E. Coronado and J. R. Galan-Mascaros, J. Mater. Chem. 2005, 15, 66-74; b) S. Dorbes, L. Valade, J. A. Real and C. Faulmann, Chem. Commun. 2005, 69-71.

[4] a) J.-F. Letard, S. Montant, P. Guionneau, P. Martin, A. Le Calvez, E. Freysz, D. Chasseau, R. Lapouyade and O. Kahn, Chem. Commun. 1997, 745-746; b) F. Averseng, C. Lepetit, P. G. Lacroix and J. P. Tuchagues, Chem. Mater. 2000, 12, 22252229.

[5] a) A. B. Gaspar and M. Seredyuk, Coord. Chem. Rev. 2014, 268, 41-58; b) A. B. Gaspar, M. Seredyuk and P. Gütlich, Coord. Chem. Rev. 2009, 253, 2399-2413.

[6] a) U. Stebani, G. Lattermann, M. Wittenberg and J. H. Wendorff, Angew. Chem., Int. Ed. Engl. 1996, 35, 1858-1861; b) V. S. Mironov, Y. G. Galyametdinov, A. Ceulemans and K. Binnemans, J. Chem. Phys. 2000, 113, 10293-10303; c) J. Barbera, R. Gimenez, M. Marcos, J. L. Serrano, P. J. Alonso and J. I. Martinez, Chem. Mater. 2003, 15, 958-964; d) M. Seredyuk, A. B. Gaspar, V. Ksenofontov, Y. Galyametdinov, J. Kusz and P. Gütlich, J. Am. Chem. Soc. 2008, 130, 1431-1439.

[7] M. F. Tweedle and L. J. Wilson, J. Am. Chem. Soc. 1976, 98, 48244834.

[8] a) C. Gandolfi, N. Miyashita, D. G. Kurth, P. N. Martinho, G. G. Morgan and M. Albrecht, Dalton Trans. 2010, 39, 4508-4516; b) C. J. Johnson, G. G. Morgan and M. Albrecht, J. Mat. Chem. C 2015, 3, 7883-7889; c) M. Clemente-Leon, E. Coronado and M. Lopez-Jorda, Dalton Trans. 2010, 39, 4903-4910.

[9] P. N. Martinho, C. J. Harding, H. Müller-Bunz, M. Albrecht and G. G. Morgan, Eur. J. Inorg. Chem. 2010, 675-679.

[10] P. N. Martinho, T. Lemma, B. Gildea, G. Picardi, H. Müller-Bunz, R. J. Forster, T. E. Keyes, G. Redmond and G. G. Morgan, Angew. Chem. Int. Ed. 2012, 51, 11995-11999.

[11] a) E. Solomon and A. Lever, Inorganic Electronic Structure and Spectroscopy, Wiley-interscience, USA, 1999, p; b) E. I. Solomon, T. C. Brunold, M. I. Davis, J. N. Kemsley, S.-K. Lee, N. Lehnert, F. Neese, A. J. Skulan, Y.-S. Yang and J. Zhou, Chem Rev 1999, 100, 235-350. 
Entry for the Table of Contents (Please choose one layout)

Layout 1:

\section{FULL PAPER}

The high temperature magnetic and structural properties of an amphiphilic iron(III) spin crossover complex are reported. Thermal cycling reveals a scan ratedependent $20 \mathrm{~K}$ thermal hysteresis close to room temperature.

Differential scanning calorimetry and cross polarized microscopy are used to show that the magnetic switching aligns with a material change from solid to ordered liquid phase on warming.

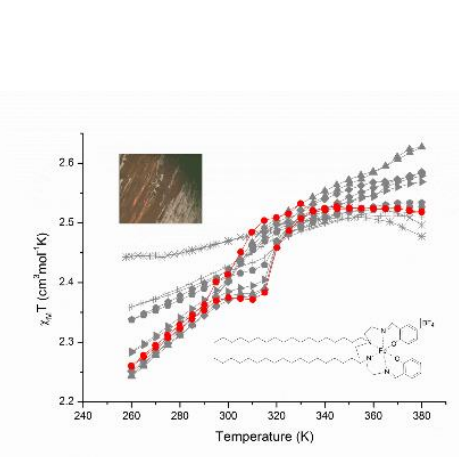

Spin Crosssover

Anthony J. Fitzpatrick, Paulo N. Martinho, a Brendan J. Gildea, John D. Holbrey, and Grace G. Morgan*

Page No. - Page No.

Robust Room Temperature Hysteresis in an Fe(III) Spin Crossover Metallomesogen

The phase change properties of an iron(III) spin crossover metallomesogen are related to its spin switching profile. 